\title{
The structure of bias in peer voting systems: lessons from the Eurovision Song Contest
}

\author{
Laura Spierdijk · Michel Vellekoop
}

Received: 15 January 2007 / Accepted: 15 December 2007 / Published online: 10 April 2008

(C) The Author(s) 2008

\begin{abstract}
This paper assesses whether and how common characteristics of jury members or peer voters affect the outcomes of voting systems. In particular, we analyze to what extent these common features result in voting bias. We take as a case study the Eurovision Song Contest for which an extensive amount of historical data is available. In contrast to earlier studies we analyze the impact of common factors on the bias individually for each country, which is necessary to substantiate the publicly debated accusations of regional block voting by certain groups of countries. We establish strong evidence for voting bias in the song contest on the basis of geography, even after correction for culture, language, religion and ethnicity. However, these effects do generally not correspond to the usual accusations. We believe that our findings extend to all instances where groups of jury members or peer voters share certain common factors, which may cause voting bias. It is important to identify such structures explicitly, as it can help avoiding bias in the first place.
\end{abstract}

The authors are grateful to Marieke van Dijk for excellent research assistance and to Laurens Swinkels, Ieva Pudane, Gijsbert van Lomwel, Jelena Stefanovic, and Bas van den Heuvel for useful comments. The usual disclaimer applies.

L. Spierdijk $(\varangle)$

Department of Economics and Econometrics, Faculty of Economics and Business, University of Groningen, P. O. Box 800, 9700 AV Groningen, The Netherlands e-mail: L.Spierdijk@rug.nl

M. Vellekoop

Financial Engineering Laboratory and the Department of Applied Mathematics,

Faculty of Electrical Engineering, Mathematics and Computer Science, University of Twente,

P. O. Box 217, 7500 AE Enschede, The Netherlands

e-mail: M.H.Vellekoop@utwente.nl 
Keywords Voting systems - Peer voting - Expert judgement - Eurovision Song Contest

\section{Introduction}

In various areas of life people judge the performance of other people through a system of jury or peer voting. Methods to detect judgement bias, and the structure of that bias, are therefore relevant in many different environments. Examples include organizations where complex decisions have to be taken based on aggregated expert opinions, sportive or cultural events where the level of quality is judged by people with different backgrounds, and peer review processes for scientific journals. Since it is relatively hard to measure bias effects in organizations, most research focuses on the latter two examples to investigate these issues, in the hope that the results extend to other cases where data is harder to obtain.

The existing literature dealing with voting and judgement behavior generally views the jury or peer voters as a single entity and ignores the possibility that there are subgroups with their own particular voting behavior. Consequently, existing studies assess the determinants of the voting bias on the aggregate level of the jury as a whole. That is, they study the average impact of an explanatory variable on the votes, where the average is taken over all jury members. This method may fail to capture all voting patterns when certain effects offset each other at the aggregate level.

The goal of this paper is to provide a framework for assessing whether and how common characteristics of voting groups affect the outcomes of voting systems and to what extent these common features result in voting bias. We take as a case study the Eurovision Song Contest for which an extensive amount of historical data is available. For this contest the assumption that all jury members behave homogeneously is particularly disputable, since the peer voters in this competition are the inhabitants of different countries. Given the substantial cultural, linguistic, religious, and macroeconomic differences between the various countries participating in the contest, it seems unrealistic to assume they all show similar voting behavior. Moreover, since the jury members in this contest are individual countries, we can construct various voting groups based on, e.g. similarities in culture, language and religion. In this way, the song contest offers a unique opportunity to investigate subjective biases in peer voting systems. That there is some systematic bias in Eurovision Contest voting can hardly be doubted when considering, e.g. Cyprus and Greece, who awarded each other with the maximal number of points in virtually all years during the period 1993-2003.

If we assume homogenous voting behavior across countries such as, e.g. Haan et al. (2005) and Ginsburgh and Noury (2006), we could ignore certain subtle voting patterns when some effects offset each other on the aggregate level. Moreover, under this assumption it is impossible to investigate the often heard suspicions and accusations that politics and international relations dictate a lot of the voting and that, e.g. some Eastern-European countries are guilty of regional block voting. Therefore, this paper starts with analyzing the voting behavior separately for each country and subsequently assesses common patterns in the votes.

We establish the following results. There is strong evidence for voting bias in the Eurovision Song Contest, but there are substantial differences in the way geographical, 
cultural, linguistic, religious, and ethnical factors influence the voting bias of individual countries. The bias of some countries mainly consists of unexplainable noise, while the votes of other participants are strongly influenced by the various factors. However, there is hardly any empirical evidence to support the usual accusations of regional block voting by certain groups of countries.

We think that our findings transcend the slightly frivolous nature of our data. In all instances where groups of jury members or peer voters share certain common factors, a voting bias related to these factors may arise. It is important to identify such structures explicitly, as it may can avoiding bias in the first place.

The setup of this paper is as follows. Section 2 briefly discusses some earlier studies dealing with the Eurovision Song Contest. Section 3 explains the rules of the contest and the data set used in this paper. In Sect. 4 we describe the variables that potentially affect the voting bias. Also, we provide some sample statistics as preliminary evidence that these variables do indeed play a role. This leads us to Sect. 5, where we describe the panel data model that explains the voting bias from several determinants. Next, Sect. 6 discuss the estimation results and investigates the robustness of the estimation results. Section 7 investigates the accusations and suspicions of regional block voting by assessing common patterns in the voting biases of the participating countries. Finally, Sect. 8 concludes.

\section{Literature review}

There is ample evidence that people are not only guided by the quality of the performance they have to judge, but by many other factors as well. For instance, the gender of the performer and its order of appearance in a competition may affect jury voting; see, e.g. Flôres and Ginsburgh (1996) who establish such serial position effects for the Queen Elisabeth music competition. Haan et al. (2005) and Bruine de Bruin (2005) find similar biases in the votes for the Eurovision Song Contest. Ginsburgh and Noury (2006), who analyze the voting behavior in the same contest, show that voters tend to favor songs coming from a related culture and sung in a similar language as their own. In the field of sports, Zitzewitz (2006) establishes nationalistic biases in Olympic winter sports judging and Bruine de Bruin (2005) finds serial position effects in World and European Figure Skating Championships.

Zitzewitz (2006) shows that for the particular example of Olympic winter sports, there is indeed bias in the judgement for some of the sports involved. The amount of bias differs quite markedly over the different sports. He shows for example that in figure skating the bias seems to be rather structured (he mentions 'vote trading' and 'block judging'), thus reinforcing the conclusions reported by Campbell and Galbraith (1996) who show that in this sport the bias seems to be particularly consistent over time. By contrasting the results for the different winter sports, Zitzewitz (2006) makes some recommendations to reduce the effect of bias. He argues that these recommendations should also be valuable in the more general setting of decision making in large organizations. ${ }^{1}$

\footnotetext{
1 See Popovic (2000) and the references therein for another example of a biased peer voting system in sports that has been investigated extensively.
} 
Another well-documented proxy for structured bias in organizations can be found in the peer reviewing of scientific publications. In a study by Link (1998), who considers all submissions to a medical journal in 1995 and 1996, a striking pattern for the bias emerges. Reviewers from both inside and outside the United States evaluate papers written by authors outside the US similarly, but papers submitted by US authors significantly more favorably. This effect was present for both US and non-US reviewers, although the effect was stronger in the first group. In a similar recent study by Ross et al. (2006) evidence is found of reviewer bias in the open review of abstracts for a medical conference. Authors prefer abstracts from the US, from English-speaking countries outside the US, and from prestigious academic institutions. Also, an experiment with blinded review suggests that this can reduce the bias, suggesting that adopting blinded peer reviews for these scientific meetings might be beneficial for a fair reviewing process.

There is an extensive amount of research available on the possible voting bias in the Eurovision Song Contest. Fenn et al. (2006) study the voting patterns in the Eurovision Song Contest during the years 1992-2003 by means of a network approach. They establish what the authors call 'voting cliques'. Additionally, they use cluster analysis to show which countries behave similarly in terms of the average number of points awarded to other countries. The results suggest some relation between countries' voting patterns based on geographical proximity. The authors conclude that the observed voting similarities are caused by a common historical or cultural background instead of just geographical proximity, but do not investigate this any further. See also Yair (1995), Yair and Maman (1996), Doosje and Haslam (2005) and Gatherer (2004, 2006).

Ginsburgh and Noury (2006) provide the most detailed statistical analysis performed so far upon the Eurovision Song contest votes. The authors distinguish 'vote trading' (where two countries exchange votes) and 'cultural voting' (where countries prefer songs from those countries which satisfy certain cultural characteristics). For the period 1975-2003, Ginsburgh and Noury (2006) test the hypothesis that votes have been exchanged in the contest. The authors find hardly any evidence for this hypothesis. By contrast, song quality plays a substantial role in explaining the voting behavior. Moreover, variables such as language and cultural characteristics turn out significant in most of their models. On average, countries prefer songs in the same language and coming from a related culture.

\section{Definitions and data}

This section discusses the rules for the Eurovision Song Contest and the data to be used in our analysis. ${ }^{2}$

\footnotetext{
2 To save space, we do not report full details about the data collection and preparation. An appendix with extensive information about the data is available from the authors upon request.
} 


\subsection{Rules of the contest}

The rules for the Eurovision Song Contest are relatively simple. Each participating country contributes a song that has not been released commercially before with a duration less than three minutes. If the song is performed by a group, there can be at most six people in it. Performers can sing in any language nowadays, even in a nonexistent language. ${ }^{3}$ However, from 1966 until 1972 and again from 1978 until 1998 songs were required to be performed in one of a country's official national languages. Each country ranks all the entries and assigns twelve points to its favorite entry, ten points to its second favorite entry, and eight through one points to its third through tenth favorites. Obviously, countries are not allowed to vote for themselves. The number of participants has always been larger than 20 in recent years, so each jury assigns zero points to many countries under this system. Voting takes place after all songs have been performed, and the country with the highest number of points wins. Since 1997 (partially) and 1998 (fully) points are awarded by televoting ${ }^{4}$ instead of professional juries in virtually all countries.

\subsection{Selection of years}

The scoring system by which each song can earn $1,2,3,4,5,6,7,8,10$ or 12 points was introduced in 1975 . Since 2004 a semi-final has been organized every year before the main competition, which partially determines which countries are going to participate during the main event. This semi-final was introduced to allow a larger number of countries to participate in the contest. We only use the years 1975-2003 (inclusive) in our analysis, a period during which the voting rules have hardly changed. The only major change in this period is the introduction of televoting in 1997/1998, when voting by telephone replaced the professional juries.

\subsection{Selection of countries}

We consider all countries that have participated at least three times in the period 19752003. These can be found in the first column of Table 1, together with the number of years in which each country participated ('\# years') and the total number of votes assigned per country ('\# votes'). The total number of votes given by all countries during the years considered amounts to 13,014. Note that, after the breakup of Yugoslavia, the countries Bosnia and Herzegovina, Slovenia, and Macedonia are treated as separate nations.

\section{Explaining the voting bias}

Since the winner of the Eurovision Song Contest is determined by a scoring system based on votes given by the participating countries themselves, suspicions and

\footnotetext{
3 Belgium chose to do so in 2003 .

4 Televoting refers to the system that allows the public to vote by phone or text message.
} 


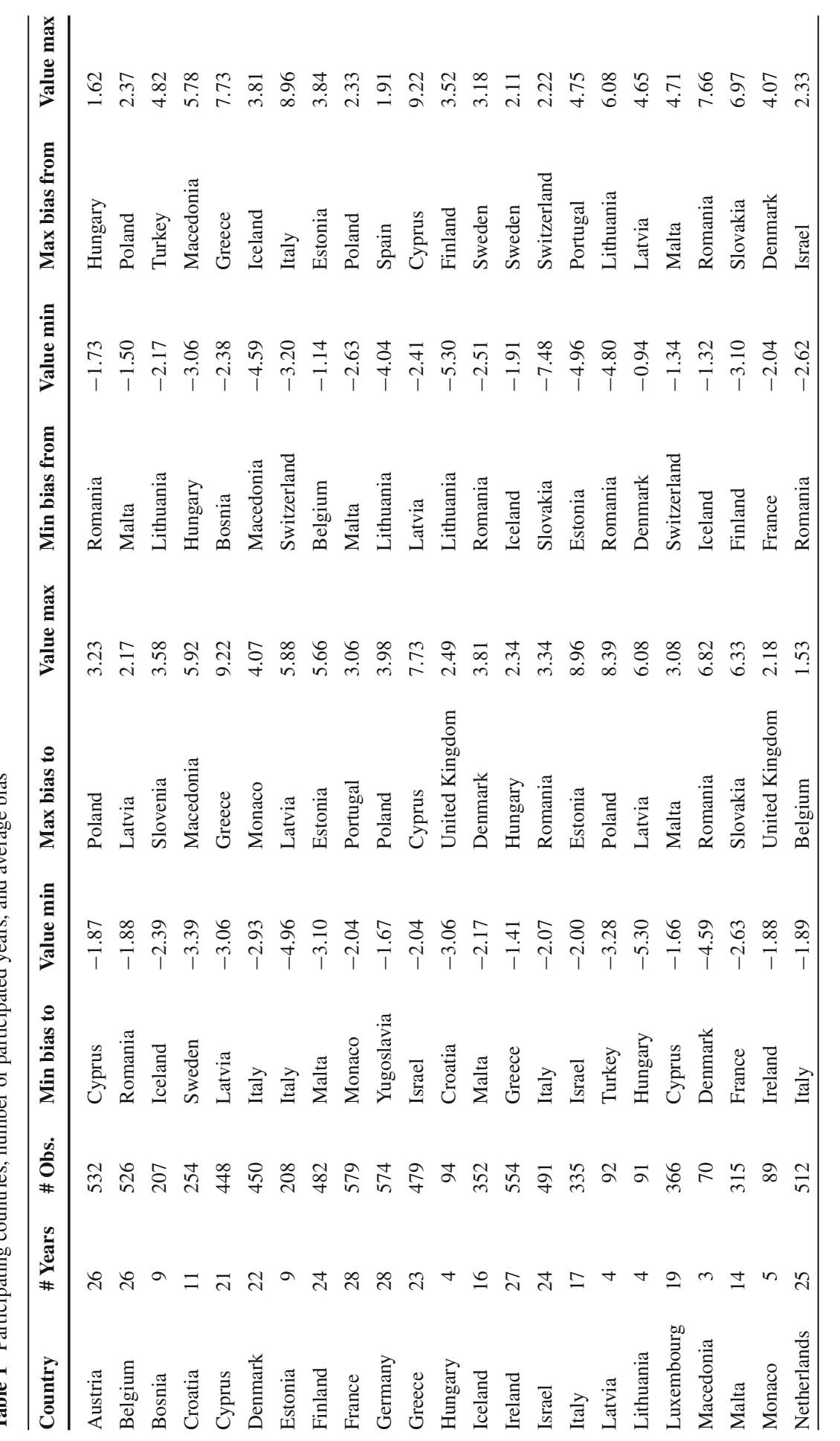




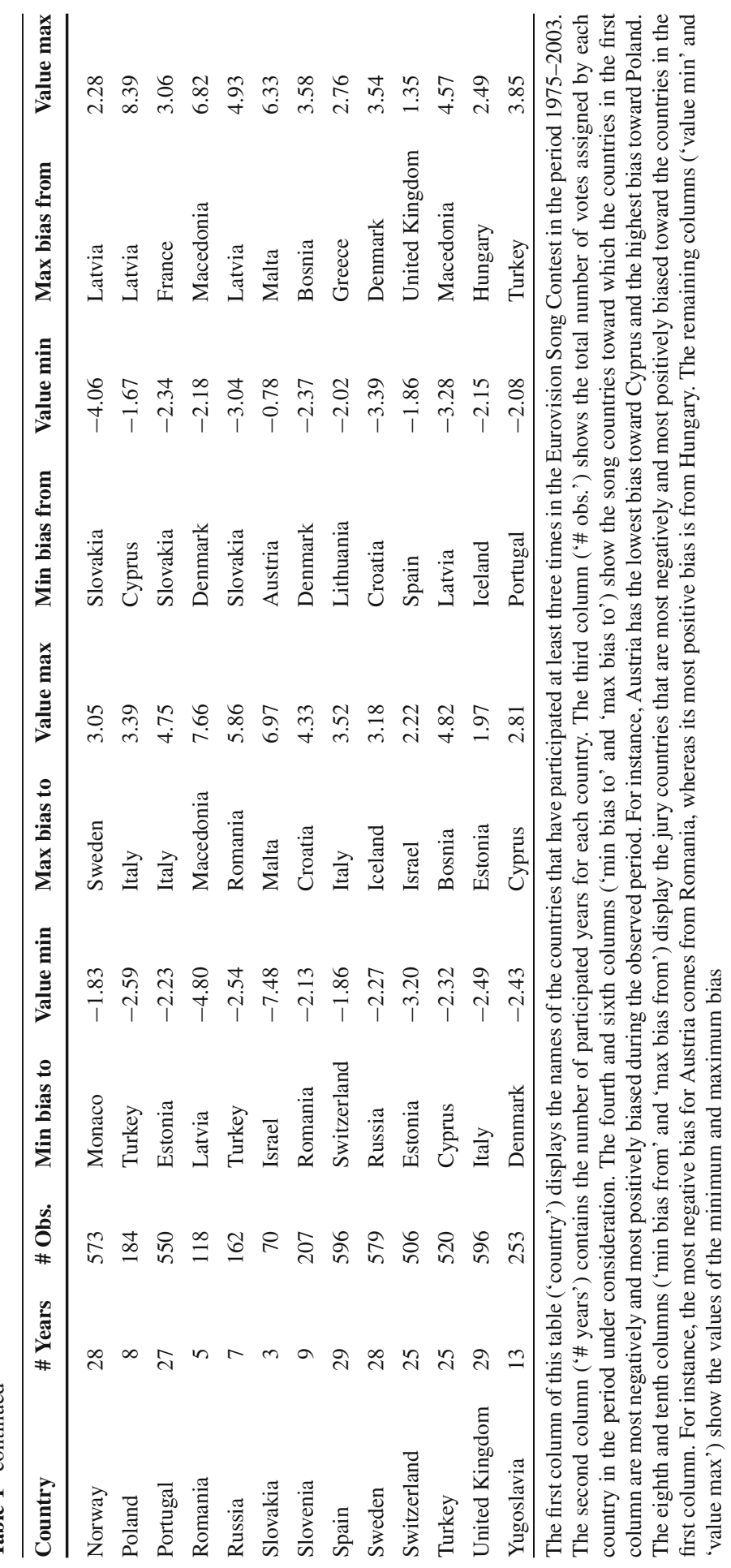


accusations of political and regional block voting are as old as the song contest itself.

To make clear that voting bias is a relative phenomenon, we turn back to the example of Greece and Cyprus who awarded each other the maximal number of points during virtually all years in the period 1993-2003. In 1992 Greece became 5th out of 23 with only eight countries giving zero points, while in 2003 it became 17 th out of 26 , with 19 countries giving zero points. It seems natural to consider the 12 points awarded to Greece by Cyprus in 2003 as a stronger indication for a bias than the 12 points awarded in 1992. This section start with the definition of voting bias and subsequently addresses the geographical, cultural, linguistic, and religious factors that potentially affect the bias in the voting behavior. Moreover, we provide some sample statistics as preliminary evidence that these factors are indeed expected to influence the votes. ${ }^{5}$

\subsection{Bias}

We start by defining the concept of bias. Let $T_{i j}$ be the number of years in which both countries $i$ and $j$ participate. Let $n_{t i j}$ be the number of countries participating in year $t$, exclusive of countries $i$ and $j$ themselves, and $s_{t i j}$ the points of jury $i$ awarded to song $j$ in year $t$. If country $i$ or $j$ does not participate in year $t$, the value of $s_{t i j}$ equals zero. The bias $b_{t i j}$ is defined as the difference between the points of jury $i$ to song $j\left(s_{t i j}\right)$ and the average number of points assigned by the other juries to song $j$ $\left(q_{t j,-i}\right)$. The average bias of jury $i$ toward song $j$ (denoted by $\bar{b}_{i j}$ ) is calculated as the time-average of the bias over those years in which both countries participate. More precisely,

$$
\begin{aligned}
q_{t j,-i} & =\frac{1}{n_{t i j}} \sum_{k \neq i} s_{t k j}, \\
b_{t i j} & =s_{t i j}-q_{t j,-i}, \\
\bar{b}_{i j} & =\frac{1}{T_{i j}} \sum_{t} b_{t i j} .
\end{aligned}
$$

When we interpret $q_{t i j}$ - the average number of points assigned by the other juries to song $j$ in year $t$-as a proxy for song quality, a large bias refers to an overvaluation and a small bias to an undervaluation of a song. Hence, when the number of points jury $i$ assigns to song $j$ is high, this does not necessarily mean that the bias of the jury is also high. This will depend on the quality of the song; i.e. on the average number of points assigned to the song by the other juries.

\subsection{Geographical influences}

In contrast to earlier studies, we explicitly consider variables related to the geographical position of a country. We include such variables to account for the often voiced

\footnotetext{
5 Throughout, we take the voting information from various Eurovision Song Contest web sites, see http:// www.eurovisioncontest.co.uk and http://members.fortunecity.com/mcdeil69/1980.htm.
} 
suspicion that these affect the votes. Most of the claims in this direction suggest that either countries which are close to each other tend to award each other a disproportionately high number of points, or that a block of 'West-European' countries and a block of 'East-European' countries tend to favor countries within their own block.

To investigate these hypotheses, we define several geographical variables. We take the longitude and latitude of the participating countries' capitals and define, for any receiving country $j$ to the west of the awarding country $i$, the variable ' $x_{i j}^{\text {west }}$ ' as the distance between country $i$ 's longitude and country $j$ 's longitude (for countries to the east of $i$ it is zero). ${ }^{6}$ For any receiving country $j$ to the east of awarding country $i$, we define ' $x_{i j}^{\text {east}}$ ' similarly, i.e. as the distance between country $i$ 's longitude and country $j$ 's longitude (for countries to the west of country $i$ it is zero). We do the

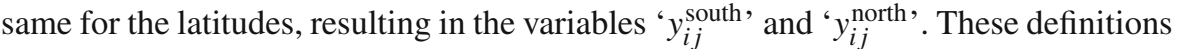
will allow us to detect a tendency to award more points to countries that are close, but also a tendency to vote for countries that are more in the East or in the West. Obviously, for some countries these variables become redundant. For example, from Iceland's point of view, all other countries are located to the east. If this is the case for a particular country, we only consider a distance variable that does not distinguish between directions. ${ }^{7}$ We also define a dummy variable 'neighb ${ }_{i j}$ ' to indicate whether two countries share a border on land. This variable is redundant in some cases, for instance for islands and for countries with neigbors which do not participate in the contest when they do. ${ }^{8}$

Table 1 displays a list of participating countries (see the column with caption 'country'). The columns with the caption 'min bias to' and 'max bias to' contain the names of the song countries to which the jury countries in the first column are most negatively and most positively biased, respectively. This column is based on the average bias over the period 1975-2003 as defined in expression (4.3). Similarly, the columns with the caption 'min bias from' and 'max bias from' display the names of the juries that are most negatively and most positively biased toward the countries in the first column. Table 1 highlights an important role for neighboring countries. Hence, some first confirmation of the claim that geographical position matters is found. The Netherlands favor Belgium, Norway favors Sweden, Germany favors Poland, Estonia favors Latvia, Lithuania favors Latvia, and Slovenia favors Croatia. Similar effects appear for countries that are not neighbors, but located relatively close to each other. For instance, Finland favors Estonia and Bosnia favors Slovenia. By contrast, France dislikes Monaco's contributions and Hungary dislikes Croatia's performances. Even stronger evidence for the relevance of geography is given by the pairs of countries (either neighbors or located relatively close to each other) that show a mutual preference for each other, such as Lithuania and Latvia, Estonia and Finland, Romania and Macedonia, and Croatia and Macedonia. ${ }^{9}$

\footnotetext{
6 We have obtained the geographical distances from http://www.wcrl.ars.usda.gov/cec/java/capitals.htm.

7 We do this for Iceland, Israel, and Russia.

8 This is the case for Cyprus, Malta, Iceland, Israel, and Yugoslavia.

9 A complete overview of the average biases of individual jury countries to song countries is available from the authors upon request.
} 


\subsection{Religion}

The role of religion in the Eurovision Song Contest was publicly discussed after the 2005 contest won by Greece. The runner up Malta then claimed that there was a strong bias toward Greece from other Orthodox countries. ${ }^{10}$ Although many European countries are highly secularized, religion may still be a factor of importance. It may reflect certain cultural characteristics of a country that have been established over the centuries and do not necessarily disappear when the role of religion becomes less prominent. Moreover, recent studies in the field of behavioral economics point out that religion often affects the decisions of economic agents (see, e.g. Iannacconea 1995, 1998; Kuran 1994), providing additional motivation to assess the impact of religion on the voting behavior. Because of cultural preferences we expect countries to favor songs coming from countries with the same religion.

We define dummy variables ' $\mathrm{rel}_{i j}$ ', which are one if and only if the voting country $i$ and the performing country $j$ share a major religion. ${ }^{11}$ A religion in a country is taken into account if the percentage of people adhering to this religion is either the largest among all religions, or if it is second largest with at least $20 \%$ adherence. We make this particular choice to allow for more than one major religion in a country, but only if it is substantial. Moreover, we take a $20 \%$ threshold level, since most countries under consideration have about five major religions. We distinguish the religions Roman Catholic, Orthodox, Jewish, Muslim, and Protestant (covering Lutheran, Calvinist, Reformed, Anglican, and all other non-Catholic and non-Orthodox Christian varieties). We do not use the percentages for the different religious groups as explanatory variables, since it is difficult to obtain complete and reliable figures over the years.

\subsection{Ethnicity}

Since reliable migration figures are generally hard to find, we only look at the specific case of Turkey, for which such data are widely available. The first generation of Turks came to Europe as migrant workers in the sixties. The 2004s final Report of the Independent Commission on Turkey gives an overview of countries with a substantial Turkish population. Austria, Belgium, Denmark, France, Germany, Netherlands, Sweden, Switzerland, and United Kingdom all have a substantial Turkish population, see Turkey in Europe: More than a promise? (2004). We do not use scaled versions of population numbers as explanatory variables, since even for Turkey it is difficult to obtain reliable figures for these numbers over the years. Instead, we use a dummy variable 'turkpop $i$ ' for each country. This dummy equals one if a country has a large Turkish population and is zero otherwise. Generally, we expect the Turkish voters in Europe to vote for their home country.

Some simple sample statistics provide preliminary evidence for patriotic voting. Since televoting took over from the professional juries in $1997 / 1998$, some of the

\footnotetext{
10 See http://www.eurosong.nl/NieuwsDetailUK.aspx?ID=246\&Artiest=102\&Landcode=MA.

11 We use the information provided in the CIA Factbook to determine the major religions for each country under consideration, see http://www.cia.gov/cia/publications/factbook/fields/2122.html.
} 
aforementioned countries (most notably France, Germany, and the Netherlands) have started to assign many points to the Turkish contribution. For the three countries mentioned the average bias until 1998 equals $0.0,0.8$, and 0.2 points, respectively. After 1998 these average biases increase sharply to 4.6, 6.4, and 3.1 points.

\subsection{Linguistic, cultural and performance variables}

We follow the idea of Ginsburgh and Noury (2006) and use the distances between the awarding and receiving countries' languages as an explanatory variable in our analysis. Hence, we use the results of the study of Dyen et al. (1992) on lexicostatistical distances to measure these distances on a scale from zero (closest) to one (most distant). We use the notation 'lang_dist $t_{i j}$ ' to indicate the lexicostatistical distance between the jury of country $i$ and the song of country $j$ in year $t$.

The dummy variables that we use for the features defining the characteristics of the songs speak for themselves. They characterize the song as being sung in English or French (dummies 'english ${ }_{t j}$ ' and 'french ${ }_{t j}$ '), performed by a solo male (the dummy 'male $t_{j}$ ' equals one in this case), a male-female duet (dummy 'duet $t j$ '), or a group (dummy 'group $t_{t j}$ '). Other variables identify in what order the songs are presented during the contest ('order ${ }_{t j}$ ') and whether or not the performers represent the host country in a particular year (dummy 'host ${ }_{t j}$ '). These factors are considered, as there is some evidence that the order in which performances are viewed influences the points awarded by the jury, see Flôres and Ginsburgh (1996) and Haan et al. (2005). The gender of the performer may have some influence as well, as shown for another competition in Ginsburgh and Van Ours (2003).

We use Hofstede's four cultural dimensions to capture the cultural differences among the participating countries. ${ }^{12}$ As in Ginsburgh and Noury (2006), we use the distances between the voting and the receiving countries' value for a Hofstede dimension as the explanatory variables. The four Hofstede dimensions are power distance, individualism, masculinity, and uncertainty avoidance, which are denoted by ' $\operatorname{pdi}_{i j}$ ', 'idv $v_{i j}$ ', 'mas ${ }_{i j}$ ', and 'uai ${ }_{i j}$ ', respectively. Because of cultural preferences we expect people to prefer songs coming from a similar culture and sung in a related language.

Since several studies have already analyzed the influence of variables such as language and performance characteristics on the voting behavior during the Eurovision Song Contest, we only briefly mention the relevance of these variables for the current sample. Although less than $24 \%$ of all songs is in English, they account for almost $50 \%$ of all victories. Similarly, songs performed by groups have obtained more victories $(41 \%)$ than expected on the basis of group participation (25\%). Also the order of performance seems to affect the votes. Although this order is drawn randomly each year, some places perform better or worse than expected. The last performer has the biggest advantage. This phenomenon has also been observed in other competitions, see, e.g. Flôres and Ginsburgh (1996). Finally, the host country also seems to benefit

\footnotetext{
12 The Geert Hofstede indices for cultural differences have been taken from http://www.geert-hofstede. com. See also Hofstede (1980, 1996).
} 
from its position, given that the percentage of contests won by the host country (more than $10 \%$ ) is substantially larger than expected (less than $5 \%$ ).

\section{The model}

In this section we present a panel data model to explain the voting bias of the participating countries from various determinants.

\subsection{Introduction}

The votes for the Eurovision Song Contest during the period 1975-2003 constitute a panel data set in the three dimensions time, juries, and songs. Since not all countries participate each year, the sample is unbalanced. Given the considerable size and dimension of the data set (29 years and 36 potentially participating countries leading to 13,014 votes) and the large number of explanatory variables, we need a model that is both realistic and feasible.

Our approach takes into account fixed effects. In contrast to most existing fixed effects models, we allow both intercepts and slopes to vary per jury country (see, e.g. Yaffee 2003). We opt for such a specification, since we expect variation in the way the voting behavior of different countries is determined by variables such as cultural and linguistic differences, performance features, and geographical factors.

Throughout, we take the bias defined by Eqs. (4.2) and (4.1) as the dependent variable. This has the advantage of working with a continuous variable rather than a categorical one, such as the number of points assigned from one country to another or the final ranking of a song in the contest. ${ }^{13}$

\subsection{Country-specific model}

Since our main focus is on the voting behavior of the participating countries, we initially ignore any period effects and confine the analysis for the moment to crosscountry effects. Our panel data set consists of the dependent variable $b_{t i j}$ - the bias of jury $i$ toward song $j$ in year $t$-and a corresponding $(1 \times K)$ vector of covariates $X_{t i j}$, for $t=1, \ldots, T, i=1, \ldots, N, j=1, \ldots, N$ with some missing observations. Here $T$ denotes the number of years, $N$ the number of countries under consideration, and $K$ the number of explanatory variables. For the full sample $T=29$ and $N=36$, while $K$ varies over different model specifications.

We write the initial model as

$$
b_{t i j}=\alpha_{i}+X_{t i j} \beta_{i}+\varepsilon_{t i j}, \quad \mathbb{E}\left(\varepsilon_{t i j} \mid X_{t i j}\right)=0,
$$

\footnotetext{
13 Also, since the bias represents the difference between a country's points and the quality of the song determined by the other countries, we do not need to explain the bias from song quality anymore. This approach has the advantage that it avoids the problems of circularity and endogeneity encountered by Ginsburgh and Noury (2006).
} 
where $\beta_{i}$ is a column vector of dimension $K$ and $\alpha_{i}$ an intercept. Identification of the model in Eq. (5.4) requires certain restrictions on the disturbance terms. We will discuss them later when we explain the estimation method. We stack $b_{t i j}, X_{t i j}$ and $\varepsilon_{t i j}$ in such a way that we arrive at the more compact specification

$$
b_{i}=\alpha_{i}+X_{i} \beta_{i}+\varepsilon_{i} .
$$

This notation emphasizes that we consider $N$ cross-sectional equations.

\subsection{Model estimation}

As long as all intercepts and slopes vary across jury countries, we estimate the model in Eq. (5.5) separately per country by means of ordinary least squares using all votes assigned to the other countries over the years. However, as soon as we impose any crosscountry restrictions upon the coefficients, joint estimation of all country equations is required. ${ }^{14}$

\section{Estimation results}

In this section we present the estimation results for several model specifications that relate the voting bias of the Eurovision countries to several factors, such as geographical location, religion, ethnicity, culture, and religion.

First, we estimate a model with country-specific coefficients, allowing all explanatory variables to affect the voting bias of each country in a different way. We refer to this specification as the 'country-specific' model. In the second model each variable has equal coefficients across countries (i.e. $\beta_{i}=\beta$, all $i$ ), but possibly different intercepts. We refer to this as the 'equal slopes model'. The key assumption underlying the latter model is that the explanatory variables affect the voting behavior of all participating countries in exactly the same way. The coefficients of the covariates thus reflect the average impact of the factor on the countries' voting behavior.

\subsection{Geographical factors}

The sample statistics in Sect. 4.2 suggest that the voting behavior of participating countries contains a strong geographical factor. To test this in a more formal way, we estimate, for each country, the model of Eq. (5.5). The full list of explanatory variables contained in the vector $X_{t i j}$ is provided in Table 2 .

\footnotetext{
14 Throughout, we use White (1980)'s robust covariance matrix to correct for (cross-sectional) heteroskedasticity. When the disturbance terms would additionally feature cross-sectional correlation, a seemingly unrelated regression (SUR) setup would yield more efficient estimates than pooled estimation. However, the unbalanced sample requires maximum likelihood (ML) estimation of the SUR model (rather than per equation estimation combined with feasible generalized least squares as in the case of an balanced sample). Because of the large amount of coefficients and the substantial number of observations, ML estimation is practically infeasible. Therefore, we do not consider the SUR model and assume that there is no crosssectional correlation among the residuals.
} 
Table 2 Potential determinants of voting bias

\begin{tabular}{|c|c|}
\hline \multicolumn{2}{|l|}{ Geography } \\
\hline$x_{i j}^{\text {east }}$ & $\begin{array}{l}\text { Longitudinal distance between capitals of } i \text { and } j \text {, if } j \text { located to the east of } i \text {; } \\
\text { zero otherwise }\end{array}$ \\
\hline$x_{i j}^{\text {west }}$ & $\begin{array}{l}\text { Longitudinal distance between capitals of } i \text { and } j \text {, if } j \text { located to the west of } i \text {; } \\
\text { zero otherwise }\end{array}$ \\
\hline$y_{i j}^{\text {north }}$ & $\begin{array}{l}\text { Latitudinal distance between capitals of } i \text { and } j \text {, if } j \text { located to the north of } i \text {; zero } \\
\text { otherwise }\end{array}$ \\
\hline$y_{i j}^{\text {south }}$ & $\begin{array}{l}\text { Latitudinal distance between capitals of } i \text { and } j \text {, if } j \text { located to the south of } i \text {; } \\
\text { zero otherwise }\end{array}$ \\
\hline Neighb $_{i j}$ & One if countries $i$ and $j$ are neighbors, zero otherwise \\
\hline \multicolumn{2}{|l|}{ Language } \\
\hline Lang_dist $t i j$ & Distance between language(s) of $i$ and (song of) $j$ in year $t$ \\
\hline \multicolumn{2}{|l|}{ Performance } \\
\hline Male $_{t j}$ & One if song of $j$ in year $t$ was sung by male solo singer, zero otherwise \\
\hline Duet $_{t j}$ & One if song of $j$ in year $t$ was sung by male-female duet, zero otherwise \\
\hline Group $_{t j}$ & One if song of $j$ in year $t$ was performed by a group, zero otherwise \\
\hline English $_{t j}$ & One if song of $j$ in year $t$ was sung in English, zero otherwise \\
\hline French $_{t j}$ & One if song of $j$ in year $t$ was sung in French, zero otherwise \\
\hline Host $_{t j}$ & One if country $j$ was the host in year $t$, zero otherwise \\
\hline Order $_{t j}$ & Order of song of $j$ in year $t$ ( 1 is first song that was sung) \\
\hline \multicolumn{2}{|c|}{ Cultural dimensions } \\
\hline $\operatorname{pdi}_{i j}$ & Distance between power distance indices of countries $i$ and $j$ \\
\hline $\operatorname{idv}_{i j}$ & Distance between individualism indices of $i$ and $j$ \\
\hline $\operatorname{mas}_{i j}$ & Distance between masculinity indices of $i$ and $j$ \\
\hline uai $_{i j}$ & Distance between uncertainty avoidance indices of $i$ and $j$ \\
\hline \multicolumn{2}{|l|}{ Religion } \\
\hline $\operatorname{rel}_{i j}$ & One if countries $i$ and $j$ share at least one major religion, zero otherwise \\
\hline \multicolumn{2}{|l|}{ Ethnicity } \\
\hline Turkpop $_{i}$ & One if country $i$ has a substantial population with Turkish roots, zero otherwise \\
\hline
\end{tabular}

The estimation results in Table 3 show that the voting biases of 14 out of 36 countries are significantly affected by their distance to other countries. As motivated in Sect. 4.2, we distinguish between distance in four directions (north, east, south, and west). Regarding horizontal distance, the bias in the votes to countries close by is generally higher than to countries that are located further away (with Luxembourg and Slovakia as exceptions). Juries do not show a clear preference for songs coming from, geographically speaking, more western or eastern countries. The number of juries that significantly dislike songs from countries to their west is virtually the same as the number of countries that dislikes contributions coming from their east. Moreover, some juries have a higher voting bias toward all countries close by, independently of the direction (see Austria, Estonia, Germany, Macedonia, and Turkey). Very different results are established for the effects of the vertical distances between capitals. Among the juries for which the vertical distance significantly affects the bias, countries 
Table 3 Estimation results for bias models

\begin{tabular}{|c|c|c|c|c|c|c|}
\hline & $x^{\text {east }}$ & $x^{\text {west }}$ & $y^{\text {north }}$ & $y^{\text {south }}$ & Neighb & Lang_dist \\
\hline Austria & $-0.15(-2.41)$ & $-\mathbf{0 . 1 7}(-2.88)$ & & & & \\
\hline \multicolumn{7}{|l|}{ Belgium } \\
\hline Bosnia & $-0.16(-2.54)$ & & & $-\mathbf{0 . 1 1}(-2.94)$ & & \\
\hline Croatia & & & & & & $-2.60(-2.12)$ \\
\hline Cyprus & & & & & & $-7.32(-6.75)$ \\
\hline Denmark & & & & & & $-\mathbf{2 . 9 0}(-3.81)$ \\
\hline Estonia & $-\mathbf{0 . 1 0}(-4.37)$ & $-\mathbf{0 . 1 1}(-3.74)$ & & & $\mathbf{3 . 7 9}(3.84)$ & \\
\hline Finland & & & $-\mathbf{0 . 4 5}(-2.81)$ & & & \\
\hline \multicolumn{7}{|l|}{ France } \\
\hline Germany & $-0.08(-2.00)$ & $-\mathbf{0 . 1 1}(-2.49)$ & & $0.07(2.56)$ & & \\
\hline Greece & & & & & & $-7.44(-4.85)$ \\
\hline Hungary & & $-0.29(-1.96)$ & & & & \\
\hline \multicolumn{7}{|l|}{ Iceland } \\
\hline \multicolumn{7}{|l|}{ Ireland } \\
\hline \multicolumn{7}{|l|}{ Israel } \\
\hline \multicolumn{7}{|l|}{ Italy } \\
\hline Latvia & & & & & $3.76(2.39)$ & \\
\hline Lithuania & & & & & $3.77(2.12)$ & \\
\hline Luxembourg & & $0.17(2.45)$ & & & & \\
\hline Macedonia & $-0.21(-2.33)$ & $-0.30(-2.41)$ & & & $-3.32(-2.03)$ & \\
\hline Malta & & & & & & $3.25(2.16)$ \\
\hline \multicolumn{7}{|l|}{ Monaco } \\
\hline \multicolumn{7}{|l|}{ Netherlands } \\
\hline Norway & & & & & & $-1.54(-2.03)$ \\
\hline \multicolumn{7}{|l|}{ Poland } \\
\hline Portugal & & & & $0.06(2.27)$ & & $-\mathbf{2 . 5 3}(-2.58)$ \\
\hline \multicolumn{7}{|l|}{ Romania } \\
\hline \multicolumn{7}{|l|}{ Russia } \\
\hline Slovakia & & $\mathbf{0 . 5 2}(2.86)$ & $-\mathbf{0 . 1 4}(-3.38)$ & $-\mathbf{0 . 2 9}(-3.26)$ & $2.45(2.52)$ & \\
\hline Slovenia & & & & & $\mathbf{2 . 4 5}(2.82)$ & $-3.89(-2.85)$ \\
\hline Spain & & & & & & $-\mathbf{2 . 8 1}(-2.92)$ \\
\hline Sweden & & & $0.06(2.33)$ & & & \\
\hline Switzerland & & & & $0.11(2.28)$ & $1.51(2.54)$ & $2.00(2.54)$ \\
\hline Turkey & $-\mathbf{0 . 3 0}(-3.30)$ & $-0.07(-2.36)$ & $0.03(1.98)$ & & & \\
\hline \multicolumn{7}{|l|}{ United } \\
\hline Kingdom & & & $0.06(2.65)$ & $\mathbf{0 . 1 2}(3.47)$ & & $-\mathbf{2 . 1 4}(-2.83)$ \\
\hline \multicolumn{7}{|l|}{ Yugoslavia } \\
\hline Equal slopes & $-\mathbf{0 . 0 2 4}(-4.02)$ & $-\mathbf{0 . 0 4 5}(-7.37)$ & & $\mathbf{0 . 0 1 4}(3.82)$ & & $-\mathbf{1 . 0 4}(-7.42)$ \\
\hline
\end{tabular}

Table 3 displays the estimation results for the country-specific model in Eq. (5.5), apart from the last row. This row shows the estimation results for the model in Eq. (5.4) with equal slopes across all countries (but possibly different intercepts). The tables only report coefficients that are significant at at least a 5\% significance level. The $t$ values in parentheses have been obtained from White (1980)s heteroskedasticity robust covariance matrix. Coefficients not in bold face are significant at a 5\% confidence level; those in bold face are significant at a $1 \%$ level. Country-specific intercepts are not displayed 
generally show higher biases toward countries that are located relatively far way in a vertical sense (with exception of Bosnia, Finland, and Slovakia). Again, juries show no particular preference for countries that are, in geographical terms, more to their north or south. Furthermore, for 6 out of 36 countries (Estonia, Latvia, Lithuania, Slovakia, Slovenia, and Switzerland) the voting bias to neighboring countries is significantly higher than to other countries, while for Macedonia it is significantly lower. For the remaining 29 countries, there are no significant neighbor effects.

We assess the average impact of the geographical variables on the voting bias by means of the equal-slopes model. The lower panel of Table 3 ('equal slopes') shows that the average neighbor effect is insignificant. However, distance effects do play a role in the equal-slopes model. On average, juries favor countries closer by in terms of horizontal distance, but at the same time, they favor countries further away to the south. Clearly, these results do not provide sufficient evidence for a 'battle' between Eastern and Western Europe as is often suggested. Nevertheless, on average juries favor countries located on the same geographical width. This means that western (eastern) countries are positively biased toward other western (eastern) countries.

\subsection{Religion}

The estimation results in Table 5 show that religion significantly influences the voting bias of six countries, even after the correction for cultural and linguistic differences and similarities between countries. Bosnia favors countries it does not share a main religion with, while Cyprus, Iceland, Ireland, Latvia, and the United Kingdom show opposite behavior. These countries favor countries with the same religion. The significant role of religion in the voting behavior of Cyprus and Ireland does not come as a complete surprise. Ireland is known as a deeply Catholic nation, whereas Cyprus has a strong Orthodox tradition. The preferences of Bosnia for non-Muslim countries might be related to the relatively large non-Muslim population in this country (Orthodox and Roman Catholics) that put their mark on the votes. When we estimate the model separately for the periods before and after the introduction of televoting in 1997/1998, we see that the effect of religion is most pronounced in the televoting period. For the professional juries religion played a less important role than for the televoting public. Religion also turns out significantly positive in the equal-slopes model; see the lower panel of Table 5 ('equal slopes'). This means that, on average, countries are positively biased toward countries with the same religious background.

\subsection{Ethnicity}

The sample statistics in Sect. 4.4 suggest that countries with a substantial Turkish population are strongly biased toward the Turkish contribution to the song contest. To make this more precise, we include the dummy variable for Turkish migration in the model of Eq. (5.5), assuming that the impact of this variable on the bias to the Turkish contribution does not depend on the voting country. Since the dummy variable does only vary over jury countries and not over time or songs, we have to 
impose this restriction for the purpose of identification. ${ }^{15}$ The estimation results show that the countries with a substantial population with Turkish roots have a significantly higher voting bias toward Turkey. We refer to this phenomenon as patriotic voting. The estimated coefficient of the Turkish migration dummy has a value of 0.61 , with a corresponding $t$ value of 2.49. To save space we do not report the estimation results for the other coefficients in the model, but we notice that they are similar to the ones obtained in the previous model without a role for Turkish nationality. When we estimate the model separately for the periods before and after the introduction of televoting in 1997/1998, it becomes clear that Turkish migration plays a significant role both before and after the start of the new voting system. However, the effect in the second period is stronger than in the first. Hence, the substantial effect of Turkish migration in the time-invariant model is mainly due to the televoting period.

The Turkish migration dummy is also significant positively in the model with constant slopes. Its coefficient has a value of 0.95 and corresponding $t$ value 4.55. This means that, on average, the votes of countries with Turkish immigrants are positively biased toward Turkey. Again, we do not report the full estimation results for the model with constant slopes, as they are similar to the ones reported in the lower panel of Tables 3, 4, 5 ('equal slopes').

\subsection{Language, culture, and other variables}

The estimation results in Tables 3, 4, 5 make clear that there are considerable differences across countries. For instance, some juries favor songs coming from a culture that substantially differs from their own in terms of one or more Hofstede dimensions (e.g. Portugal with individualism). On average, as expected from cultural preferences, juries have significantly higher biases toward songs in a related language and to songs coming from a similar culture. However, some variables that on the aggregate level do not exert a significant effect on the bias, significantly influence the bias of individual countries (the duet, group, and male dummy variables, as well as the dummy for songs sung in English); see the last row of Tables 3, 4, 5. This vindicates again the need for our approach, in which countries are considered separately when analyzing voting bias effects.

\section{Structural effects in voting bias}

The individual (adjusted) $R^{2}$ 's in Table 5 exhibit substantial variation across countries. For some countries the $R^{2}$ is high, while for other countries it is close to zero. By comparing the $R^{2}$ 's across countries, we can distinguish two groups of countries. The first group contains the countries for which the voting bias mainly consists of unexplainable noise. By contrast, the biases in the second group are strongly influenced by the factors we consider. It is tempting to conclude that the countries with unexplainable biases

\footnotetext{
15 This also means that we cannot estimate the resulting equations separately for individual countries, but instead have to rely on joint (least squares) estimation of the panel model for all countries.
} 
Table 4 Estimation results for bias models (continued)

\begin{tabular}{|c|c|c|c|c|c|c|c|}
\hline & Male & Duet & Group & English & French & Host & Order \\
\hline \multicolumn{8}{|l|}{ Austria } \\
\hline Belgium & & & & & & $\begin{array}{l}-1.38 \\
(-2.23)\end{array}$ & \\
\hline \multicolumn{8}{|l|}{ Bosnia } \\
\hline Croatia & & & & & $\begin{array}{l}-\mathbf{2 . 3 8} \\
(-2.97)\end{array}$ & & $\begin{array}{l}-1.38 \\
(-2.03)\end{array}$ \\
\hline Cyprus & & & & & & & $\begin{array}{l}-0.96 \\
(-2.05)\end{array}$ \\
\hline Denmark & $\begin{array}{l}\mathbf{1 . 0 8} \\
(2.96)\end{array}$ & & $\begin{array}{l}\mathbf{0 . 8 8} \\
(2.90)\end{array}$ & & & & \\
\hline Estonia & & & & & & & $\begin{array}{l}1.34 \\
(2.60)\end{array}$ \\
\hline \multicolumn{8}{|l|}{ Finland } \\
\hline France & & & & $\begin{array}{l}-\mathbf{1 . 3 0} \\
(-3.62)\end{array}$ & & & \\
\hline \multicolumn{8}{|l|}{ Germany } \\
\hline Greece & $\begin{array}{l}\mathbf{0 . 9 7} \\
(2.61)\end{array}$ & & & & & $\begin{array}{l}-1.64 \\
(-2.16)\end{array}$ & \\
\hline Hungary & & & & & & & $\begin{array}{l}1.48 \\
(2.20)\end{array}$ \\
\hline Iceland & $\begin{array}{l}-0.91 \\
(-2.52)\end{array}$ & & & & & & \\
\hline Ireland & & & & & $\begin{array}{l}1.14 \\
(2.03)\end{array}$ & & \\
\hline Israel & $\begin{array}{l}-0.67 \\
(-2.02)\end{array}$ & & & & & & \\
\hline Italy & & & $\begin{array}{l}-0.92 \\
(-2.05)\end{array}$ & & & & $\begin{array}{l}-2.07 \\
(-3.27)\end{array}$ \\
\hline Latvia & & & $\begin{array}{l}2.47 \\
(2.79)\end{array}$ & & $\begin{array}{l}1.37 \\
(2.07)\end{array}$ & & \\
\hline Lithuania & & $\begin{array}{l}-\mathbf{2 . 2 5} \\
(-2.77)\end{array}$ & & $\begin{array}{l}\mathbf{2 . 0 1} \\
(3.24)\end{array}$ & $\begin{array}{l}1.78 \\
(1.96)\end{array}$ & & \\
\hline \multicolumn{8}{|l|}{ Luxembourg } \\
\hline Macedonia & & & & & & $\begin{array}{l}4.52 \\
(3.94)\end{array}$ & \\
\hline Malta & & & & $\begin{array}{l}2.67 \\
(2.69)\end{array}$ & & & \\
\hline \multicolumn{8}{|l|}{ Monaco } \\
\hline Netherlands & $\begin{array}{l}-0.78 \\
(-2.51)\end{array}$ & $\begin{array}{l}-1.27 \\
(-2.50)\end{array}$ & $\begin{array}{l}-0.67 \\
(-2.06)\end{array}$ & & $\begin{array}{l}1.50 \\
(2.55)\end{array}$ & & \\
\hline \multicolumn{8}{|l|}{ Norway } \\
\hline Poland & & & & & & & $\begin{array}{l}\mathbf{2 . 5 1} \\
(4.27)\end{array}$ \\
\hline \multicolumn{8}{|l|}{ Portugal } \\
\hline Romania & & & & & & & \\
\hline
\end{tabular}


Table 4 continued

\begin{tabular}{|c|c|c|c|c|c|c|c|}
\hline & Male & Duet & Group & English & French & Host & Order \\
\hline \multicolumn{8}{|l|}{ Russia } \\
\hline Slovakia & $\begin{array}{l}2.47 \\
(2.04)\end{array}$ & & & & & $\begin{array}{l}-\mathbf{5 . 6 1} \\
(-5.67)\end{array}$ & \\
\hline Slovenia & & $\begin{array}{l}1.33 \\
(2.39)\end{array}$ & & $\begin{array}{l}-0.79 \\
(-2.05)\end{array}$ & & & \\
\hline Spain & & & & & $\begin{array}{l}-\mathbf{2 . 3 4} \\
(-3.63)\end{array}$ & & \\
\hline Sweden & & & & $\begin{array}{l}0.94 \\
(2.48)\end{array}$ & & & \\
\hline Switzerland & & & $\begin{array}{l}-0.64 \\
(-2.13)\end{array}$ & $\begin{array}{l}\mathbf{1 . 1 0} \\
(2.75)\end{array}$ & & $\begin{array}{l}-\mathbf{1 . 6 2} \\
(-2.68)\end{array}$ & \\
\hline Turkey & & & & & $\begin{array}{l}-\mathbf{2 . 2 8} \\
(-4.34)\end{array}$ & & \\
\hline United Kingdom & & & & & $\begin{array}{l}0.94 \\
(1.96)\end{array}$ & & \\
\hline \multicolumn{8}{|l|}{ Yugoslavia } \\
\hline Equal slopes & & & & & $\begin{array}{l}-0.23 \\
(-2.48)\end{array}$ & & \\
\hline
\end{tabular}

vote objectively, but this would be too bold as we may have omitted some important explanatory variables in our model.

The adjusted $R^{2}$ corresponding to the equal-slopes model gives a totally different impression of the voting bias, as its low value (0.022) suggests that the economic relevance of the voting bias is limited. By contrast, the country-specific analysis shows that for many individual countries the economic impact of the voting bias is substantial. At the one hand, this underlines the importance of taking into account the differences among the various countries for proper assessment of the structure of the voting bias. ${ }^{16}$ On the other hand, the low overall $R^{2}$ points out that the economic importance of the factors influencing the voting bias is small on the aggregate level, although their influence is statistically significant. Apparently, the biases of individual countries caused by certain factors disappear on the aggregate level as they are offset by opposite preferences of other countries or in different years. ${ }^{17}$ This suggests that, on the aggregate level, jury diversity can diminish the impact of particular factors on the voting bias by making it more likely that the biases of individual jury members are offset by opposite preferences of other members.

During virtually all Eurovision Song Contests, there have been accusations that some groups of countries are guilty of regional block voting and also some studies on

\footnotetext{
16 More formally, a Wald test provides more evidence in favor of the country-specific model. The constantslope model is rejected in favor of the country-specific model at a 5\% significance level. Additionally, for all explanatory variables the null hypothesis of similar coefficients across countries is rejected at the same significance level. Hence, the voting behavior differs substantially across countries.

17 The overall adjusted $R^{2}$ was lower during the period before the introduction of televoting $(0.017)$ and much higher thereafter $(0.080)$. But even for the televoting period the adjusted $R^{2}$ is relatively low.
} 
Table 5 Estimation results for bias models (continued)

\begin{tabular}{|c|c|c|c|c|c|c|c|c|}
\hline & pdi & $\mathrm{idv}$ & mas & uai & rel & $R^{2}$ & adj. $R^{2}$ & \# obs \\
\hline Austria & $\begin{array}{l}-0.017 \\
(-2.06)\end{array}$ & & & & & 0.050 & 0.017 & 532 \\
\hline Belgium & $\begin{array}{l}0.023 \\
(2.16)\end{array}$ & & & & & 0.052 & 0.019 & 526 \\
\hline Bosnia & & & $\begin{array}{l}-0.055 \\
(-2.23)\end{array}$ & & $\begin{array}{l}-1.61 \\
(-2.22)\end{array}$ & 0.151 & 0.069 & 207 \\
\hline Croatia & & & & & & 0.235 & 0.176 & 254 \\
\hline Cyprus & & & & & $\begin{array}{l}1.71 \\
(2.10)\end{array}$ & 0.286 & 0.258 & 448 \\
\hline Denmark & & & & & & 0.189 & 0.155 & 450 \\
\hline Estonia & & $\begin{array}{c}-\mathbf{0 . 0 6 0} \\
(-3.31)\end{array}$ & & $\begin{array}{l}0.031 \\
(2.28)\end{array}$ & & 0.380 & 0.325 & 208 \\
\hline Finland & & & & & & 0.040 & 0.004 & 482 \\
\hline France & & & & & & 0.061 & 0.031 & 579 \\
\hline Germany & & $\begin{array}{l}-0.039 \\
(-2.30)\end{array}$ & $\begin{array}{l}0.015 \\
(1.98)\end{array}$ & & & 0.033 & 0.002 & 574 \\
\hline Greece & & & & & & 0.233 & 0.203 & 479 \\
\hline Hungary & & & & & & 0.146 & -0.045 & 94 \\
\hline Iceland & & $\begin{array}{l}-0.048 \\
(-2.14)\end{array}$ & $\begin{array}{l}-0.017 \\
(-2.03)\end{array}$ & $\begin{array}{l}\mathbf{0 . 0 4 1} \\
(2.99)\end{array}$ & $\begin{array}{l}1.64 \\
(2.38)\end{array}$ & 0.163 & 0.126 & 352 \\
\hline Ireland & $\begin{array}{l}-0.026 \\
(-2.00)\end{array}$ & & & & $\begin{array}{l}1.21 \\
(2.29)\end{array}$ & 0.058 & 0.026 & 554 \\
\hline Israel & & & & & & 0.029 & 0.003 & 491 \\
\hline Italy & & & & $\begin{array}{l}-0.031 \\
(-2.16)\end{array}$ & & 0.098 & 0.047 & 335 \\
\hline Latvia & & & & & $\begin{array}{l}\mathbf{2 . 2 7} \\
(3.02)\end{array}$ & 0.412 & 0.267 & 92 \\
\hline Lithuania & & & & & & 0.330 & 0.162 & 91 \\
\hline Luxembourg & & & & & & 0.047 & -0.002 & 366 \\
\hline Macedonia & & & & & & 0.361 & 0.136 & 70 \\
\hline Malta & & & & & & 0.087 & 0.034 & 315 \\
\hline Monaco & & & & & & 0.107 & -0.122 & 89 \\
\hline Netherlands & & & $\begin{array}{l}-0.019 \\
(-2.11)\end{array}$ & & & 0.074 & 0.040 & 512 \\
\hline Norway & & $\begin{array}{l}-0.033 \\
(-2.03)\end{array}$ & $\begin{array}{l}-0.018 \\
(-2.24)\end{array}$ & $\begin{array}{l}0.029 \\
(2.45)\end{array}$ & & 0.091 & 0.062 & 573 \\
\hline Poland & & $\begin{array}{l}-0.046 \\
(-2.12)\end{array}$ & & & & 0.240 & 0.157 & 184 \\
\hline Portugal & & $\begin{array}{l}\mathbf{0 . 0 5 3} \\
(3.77)\end{array}$ & & & & 0.092 & 0.061 & 550 \\
\hline Romania & & & & & & 0.183 & 0.034 & 118 \\
\hline Russia & & & & & & 0.054 & -0.058 & 162 \\
\hline Slovakia & & & & & & 0.516 & 0.345 & 70 \\
\hline
\end{tabular}


Table 5 continued

\begin{tabular}{|c|c|c|c|c|c|c|c|c|}
\hline & pdi & idv & mas & uai & rel & $R^{2}$ & adj. $R^{2}$ & \# obs \\
\hline Slovenia & & & $\begin{array}{l}-0.026 \\
(-2.08)\end{array}$ & & & 0.202 & 0.125 & 207 \\
\hline Spain & $\begin{array}{l}-0.024 \\
(-1.96)\end{array}$ & & & & & 0.078 & 0.050 & 596 \\
\hline Sweden & & & & & & 0.142 & 0.114 & 579 \\
\hline Switzerland & & $\begin{array}{l}-\mathbf{0 . 0 6 6} \\
(-3.55)\end{array}$ & & & & 0.099 & 0.066 & 506 \\
\hline Turkey & & & & $\begin{array}{l}-\mathbf{0 . 0 4 0} \\
(-3.25)\end{array}$ & & 0.129 & 0.100 & 520 \\
\hline United Kingdom & $\begin{array}{l}-\mathbf{0 . 0 3 9} \\
(-3.16)\end{array}$ & & & & $\begin{array}{l}1.11 \\
(1.97)\end{array}$ & 0.076 & 0.047 & 596 \\
\hline Yugoslavia & $\begin{array}{l}-0.038 \\
(-2.06)\end{array}$ & & $\begin{array}{l}0.077 \\
(2.04)\end{array}$ & & & 0.104 & 0.040 & 253 \\
\hline Equal slopes & $\begin{array}{l}-\mathbf{0 . 0 0 6} \\
(-3.12)\end{array}$ & & $\begin{array}{l}-\mathbf{0 . 0 0 5} \\
(-3.01)\end{array}$ & & $\begin{array}{l}0.193 \\
(2.47)\end{array}$ & 0.026 & 0.022 & 13,014 \\
\hline
\end{tabular}

the song contest establish block voting, e.g. Gatherer (2004) and Fenn et al. (2006). The accusations are particularly directed against the Baltic states, the former Republic of Yugoslavia, Scandinavian countries, and Greece and Cyprus. Our country-specific analysis allows us to investigate the accusations in more detail. The influence of cultural, linguistic, religious and ethnical factors on the votes can be explained by human behavior. However, when geographical variables turn out significant even after correction for the former factors, this raises the suspicion that there is 'political' voting. That is, there seems no other way to explain the influence of geographical factors on the voting bias. Hence, when we verify the usual accusations of political voting and regional block voting, we look at significant geographical effects after correction for cultural, linguistic, religious and ethnical variables.

Looking at the Baltic countries, we observe that Estonia, Latvia and Lithuania all tend to give significantly more points to neighboring countries. Additionally, Estonia also favors countries which are roughly on the same meridian; these include Finland, Latvia, and Lithuania. For the Nordic countries, the pattern is more subtle. If Finland, for example, would favor the other Nordic countries, we would expect it to prefer countries to its west, and to dislike those to its south. Neither of those is true. For the other Scandinavian countries, none of the geographical features turns out to be significant, apart from Sweden's preferences for countries to its north. That seems to indicate a preference for other Nordic countries, since only Iceland, Finland and Norway are to its north according to our definitions. However, the influence seems weak and one would additionally expect the neighbor variable to be significant for Sweden as well, but it is not. There are strong indications that culture plays an important role in the voting of both Norway and Iceland, since some of the Hofstede dimensions are significant for these countries. On the other hand, the relatively high explanatory power of the model for the voting bias of Denmark and Sweden seems to be caused mainly by song characteristics. Also language plays an important role in all of these 
countries apart from Iceland, where instead there is an influence based on religious background.

Regarding the former states of the Republic of Yugoslavia, the only significant geographical influences that have been established are connected to Slovenia and Macedonia. For these two countries neighbor and distance effects play a significant role. Possible block voting between the United Kingdom and Ireland cannot be substantiated by our research. The United Kingdom favors countries to its north, but also countries to its south.

Also Cyprus and Greece deserve further mention, as it is probably the most often cited example of Eurovision Song Contest voting bias. We see that the huge bias between Cyprus and Greece can be explained for a significant part by the common language and religious background. The language effect is influential for both countries, but the religious background is only significant for the voting of Cyprus. Our analysis shows that linguistic preferences play an important role for many countries, but the linguistic effect is by far the most significant for Cyprus and Greece.

\section{Conclusions}

This paper assesses whether and how common characteristics of voting groups affect the outcomes of voting systems and to what extent these common features result in voting bias. We take as a case study the Eurovision Song Contest for which an extensive amount of historical data is available. Rather than analyzing the voting behavior of the participating countries on the aggregate level (leading to a loss of information), we zoom in on the voting behavior of individual countries and groups of countries. In this way, we can also investigate the often heard suspicions and accusations that politics and international relations dictate a large part of the voting.

There is strong evidence for voting bias in the Eurovision Song Contest, based on geographical, cultural, linguistic, religious, and ethnical factors. Although on average countries prefer songs in a related language, coming from a country close by with a similar culture and religion, there are many countries with different preferences. For some participants the voting bias mainly consists of unexplainable noise. By contrast, the votes of other countries are strongly influenced by the various factors. Although our study uncovers significant geographical patterns in the voting biases (suggesting political voting), we find hardly any evidence for the publicly debated accusations of regional block voting by certain countries.

A lesson that we can draw from our analysis of the Eurovision Song Contest is that when accusations of biased voting are made against a jury or group of peer voters, it is not enough to analyze the votes of the jury on the aggregate level. The latter approach ignores the possibility that there are subgroups with their own particular voting behavior. Consequently, this method may fail to capture all voting patterns when certain effects offset each other at the aggregate level. We believe that our results extend to all situations where groups of jury members or peer voters share certain common factors, due to which a voting bias related to these factors may arise. It is important to identify such structures explicitly and in a proper way, as it can help avoiding bias in the first place. 
Open Access This article is distributed under the terms of the Creative Commons Attribution Noncommercial License which permits any noncommercial use, distribution, and reproduction in any medium, provided the original author(s) and source are credited.

\section{References}

Bruinen de Bruin W (2005) Save the last dance for me: unwanted serial position effects in jury evaluations. Acta Psychol 118:245-260

Campbell B, Galbraith JW (1996) Nonparametric tests of the unbiasedness of Olympic figure-skating judgments. Statistician 45:521-526

Doosje B, Haslam SA (2005) What have they done for us lately? The dynamics of reciprocity in intergroup contexts. J Appl Soc Psychol 35:508-535

Dyen I, Kruskal J, Black P (1992) An Indo-European classification: a lexicostatistical experiment. Trans Am Philos Soc 82:1-132

Fenn D, Suleman O, Efstathiou J, Johnson NF (2006) How does Europe make its mind up? Connections, cliques and compatibility between countries in the Eurovision Song Contest. Phys A 360:576-598

Flôres RG Jr, Ginsburgh VA (1996) The Queen Elizabeth competition: how fair is the final ranking? J R Stat Soc Ser D, Stat 45:97-104

Gatherer D (2006) Comparison of Eurovision Song Contest simulation with actual results reveals shifting patterns of collusive voting alliances. J Artif Soc Soc Simul 9

Gatherer D (2004) Birth of a meme: the origin and evolution of collusive voting patterns in the Eurovision Song Contest. J Memetics Evol Models Inf Transm 8

Ginsburgh V, Noury A (2006) The Eurovision Song Contest: is voting political or cultural? (Working Paper)

Ginsburgh VA, Van Ours JC (2003) Expert opinion and compensation: evidence from a musical competition. Am Econ Rev 93:289-296

Haan MA, Dijkstra G, Dijkstra PT (2005) Expert judgement versus public opinion-evidence from the Eurovision Song Contest. J Cult Econ 29:59-78

Hofstede G (1980) Culture's consequences. Sage, Beverly Hills

Hofstede G (1996) Cultures and organizations. McGraw-Hill, London

Iannaccone LR (1998) Introduction to the economics of religion. J Econ Lit 36:1465-1496

Iannaccone LR (1995) Voodoo economics? Reviewing the rational choice approach to religion. J Sci Study Relig 34:76-88

Kuran T (1994) Religious economics and the economics of religion. J Inst Theor Econ 150:769-775

Link AM (1998) US and non-US submissions. J Am Med Assoc 280:246-247

Popovic R (2000) International bias detected in judging rhythmic gymnastics competition at Sydney-2000 Olympic Games. Phys Educ Sport 11:1-3

Ross JS, Gross CP, Desai MM, Hong Y, Grant AO, Daniels SR, Hachinski VC, Gibbons RJ, Gardner TJ, Krumholz HM (2006) Effect of blinded peer review on abstract acceptance. J Am Med Assoc 295:1675-1680

Turkey in Europe: More than a promise? (2004) Publication of the Independent Commission on Turkey. http://www.independentcommissiononturkey.org/pdfs/english.pdf

White H (1980) Heteroskedasticity consistent covariance matrix estimator and a direct test for heteroskedasticity. Econometrica 48:817-838

Yaffee RA (2003) A Primer for panel data analysis. Working Paper, New York University

Yair G (1995) Unite Unite Europe. The political and cultural structures of Europe as reflected in the Eurovision Song Contest. Soc Netwrks 17:147-161

Yair G, Maman D (1996) The persistent structure of hegemony in the Eurovision Song Contest. Acta Sociol 39:309-325

Zitzewitz E (2006) Nationalism in winter sports judging and its lessons for organizational decision making. J Econ Manage Strategy 15:67-99 